\title{
Exogenous regucalcin negatively regulates the progression of cervical adenocarcinoma
}

\author{
XIAOLONG LI ${ }^{1,2^{*}}$, YINGWEN HUANG ${ }^{3 *}$, SHUNLI GUO $^{2}$, MEIYU XIE ${ }^{2}$, XIAOYUN BIN $^{2}$, \\ MINGXIA SHI ${ }^{2}$, ANNING CHEN ${ }^{2}$, SIYU CHEN ${ }^{2}$, FAN WU $^{2}$, QIPING HU ${ }^{2}$ and SUFANG ZHOU ${ }^{2,4}$
}

\begin{abstract}
Departments of ${ }^{1}$ Cell Biology and Genetics and ${ }^{2}$ Biochemistry and Molecular Biology, School of Pre-Clinical Medicine, Guangxi Medical University; ${ }^{3}$ Department of Central Laboratory, The First Affiliated Hospital of Guangxi University of Chinese Medicine; ${ }^{4}$ National Center for International Research of Biological Targeting Diagnosis and Therapy, Guangxi Key

Laboratory of Biological Targeting Diagnosis and Therapy Research, Collaborative Innovation Center for Targeting

Tumor Diagnosis and Therapy, Guangxi Medical University, Nanning, Guangxi 530000, P.R. China
\end{abstract}

Received June 20, 2018; Accepted April 15, 2019

\section{DOI: $10.3892 / \mathrm{ol} .2019 .10374$}

\begin{abstract}
Cervical adenocarcinoma (CA) is a type of cervical cancer, and in previous decades its incidence has steadily increased. The upregulation of regucalcin (RGN) in various tumor cell types inhibits the progression of cancer. To understand the role of RGN in CA, RGN expression in human cervical cancer compared with normal tissues was analyzed using The Cancer Genome Atlas database (TCGA). Subsequently, transfection of lentivirus-mediated RGN into HeLa cells was conducted to study its function in tumor proliferation and metastasis. The expression of RGN and proteins associated with the Wnt/ $\beta$-catenin signaling pathway and epithelial-mesenchymal transition (EMT) were determined using reverse transcription-quantitative polymerase chain reaction and western blotting. Cell migration and invasion were evaluated using Transwell assays. Furthermore, cell proliferation, colony formation and cell cycle were assessed using the Cell Counting Kit-8, colony formation assay and flow cytometry, respectively. Lentivirus-mediated RGN effectively upregulated RGN expression, inhibited cell proliferation, retarded cellular invasion and promoted cell cycle arrest at the $\mathrm{G}_{2} / \mathrm{M}$ phase in HeLa cells. In addition, the expression levels
\end{abstract}

Correspondence to: Professor Sufang Zhou, Department of Biochemistry and Molecular Biology, School of Pre-Clinical Medicine, Guangxi Medical University, 22 Shuangyong Road, Nanning, Guangxi 530000, P.R. China

E-mail: zsf200000@163.com

Dr Xiaolong Li, Department of Cell Biology and Genetics, School of Pre-Clinical Medicine, Guangxi Medical University, 22 Shuangyong Road, Nanning, Guangxi 530000, P.R. China

E-mail: xlongli@outlook.com

${ }^{*}$ Contributed equally

Key words: regucalcin, cervical cancer, HeLa, lentivirus, gene therapy of $\beta$-catenin, $p$-glycogen synthase kinase (GSK)-3 $\beta$, matrix metalloproteinase (MMP)-3, MMP-7 and MMP-9 were effectively decreased, whilst those of E-cadherin and GSK-3 $\beta$ were increased. The results suggest that RGN may be an inhibitory factor in tumorigenesis, and its mechanism of inhibiting tumor proliferation and metastasis may be associated with Wnt/ $\beta$-catenin signaling and EMT.

\section{Introduction}

Regucalcin (RGN), a calcium binding protein with a molecular weight of $33 \mathrm{kDa}$, was first isolated by Japanese scientists from the rat liver in the 1980s (1-4). RGN serves a principal role in the maintenance of intracellular calcium homeostasis and liver metabolism. It also influences the activities of numerous enzymes including pyruvate kinase, succinate kinase, glycogen phosphorylase and adenosine (5-8). Since the 1990s, numerous studies have reported an association between RGN and carcinoma, where the upregulation of RGN expression in various cancer types inhibited tumor growth and metastasis. A previous study demonstrated that the downregulation of RGN expression using the RNAi technique significantly enhanced the proliferation and migration capacities of HepG2 cells (9).

Cervical cancer (CC) is a common tumor, which has a high rate of morbidity and mortality in developing countries (10). According to the global cancer statistics in 2018, incidence and mortality rates of cervical cancer in women worldwide are 6.6 and $7.5 \%$, respectively (11). Cervical adenocarcinoma (CA) is a unique type of cervical cancer with an increasing rate of morbidity, even in young people $(12,13)$. Furthermore, the rate of ovarian metastasis in CA is high compared with that of squamous carcinoma, while its sensitivity to radiotherapy and chemotherapy is significantly lower (14-16). Gene therapy is becoming one of the potential therapeutic strategies for cervical cancer due to its safety and specificity (17). In the present study, exogenous RGN was transfected into HeLa cells, a human papillomavirus-associated endocervical adenocarcinoma cell line, to analyze the effect of RGN in CA, and to determine the signaling proteins involved. 


\section{Materials and methods}

Clinical association between regucalcin $(R G N)$ and cervical cancer. The clinical data for RGN expression in cervical and endocervical cancers (CESC) was derived from The Cancer Genome Atlas (TCGA) database (https://tcga-data.nci.nih. gov/tcga). RGN expression was analyzed in six aspects: principal cancer stage, individual cancer stage, patient's race, weight, age and histological subtype.

Cell culture and lentivirus infection. HeLa cells were obtained from the Chinese Academy of Sciences (Beijing, China). A lentiviral vector encoding RGN-cDNA was purchased from Shanghai GenePharma Co., Ltd. (Shanghai, China). The cDNA sequence was as follows: ATGTCTTCCATTAAGATT GAGTGTGTTTTGCCAGAGAACTGCCGGTGTGGTGAG TCTCCAGTATGGGAGGAAGTGTCCAACTCTCTGCTC TTTGTAGACATTCCTGCAAAAAAGGTTTGCCGGTGG GATTCATTCACCAAGCAAGTACAGCGAGTGACCA TGGATGCCCCAGTCAGCTCCGTGGCTCTTCGCCAGT CGGGAGGCTATGTTGCCACCATTGGAACAAAGTTCT GTGCTTTGAACTGGAAAGAACAATCAGCAGTTGTCT TGGCCACGGTGGATAACGACAAGAAAAACAATCGCT TCAATGATGGGAAGGTGGATCCCGCCGGGAGGTACT TTGCTGGCACCATGGCTGAGGAAACAGCTCCAGCAG TTCTTGAGCGGCACCAGGGGGCCCTGTACTCCCTCT TTCCTGATCACCACGTGAAAAAGTACTTTGACCAGG TGGACATTTCCAATGGTTTGGATTGGTCGCTAGACC ACAAAATCTTCTATTACATTGACAGCCTGTCCTACT CCGTGGATGCCTTTGACTATGACCTGCAGACAGGAC AGATCTCCAACCGCAGAAGTGTTTACAAGCTAGAAA AGGAAGAACAAATCCCAGATGGAATGTGTATTGATG CTGAGGGGAAGCTCTGGGTGGCCTGTTACAATGGAG GAAGAGTGATTCGTTTAGATCCTGTGACAGGGAAAA GACTTCAAACTGTGAAGTTGCCTGTTGATAAAACAA CTTCATGCTGCTTTGGAGGGAAGAATTACTCTGAAA TGTATGTGACCTGCGCCCGGGATGGGATGGACCCCG AGGGTCTTTTGAGGCAACCTGAAGCTGGTGGAATTT TCAAGATAACTGGTCTGGGGGTCAAAGGAATTGCTC CCTACTCCTATGCGGGATGA. HeLa cells were maintained in Dulbecco's modified Eagle's medium (DMEM; HyClone; GE Healthcare Life Sciences, Logan, UT, USA) supplemented with $10 \%$ fetal bovine serum (FBS; Gibco, Thermo Fisher Scientific, Inc., Waltham, MA, USA). To produce a cell line that highly expressed RGN, $5 \times 10^{5}$ cells/well were incubated overnight in a 6-well plate, and the RGN lentiviral or empty vectors were added (multiplicity of infection, 20). Following a $24 \mathrm{~h}$ infection period, the cells were treated with puromycin $(2 \mu \mathrm{g} / \mathrm{ml})$ for $72 \mathrm{~h}$ to screen for positive clones. Successfully infected cells were verified by the positive expression of green fluorescent protein.

Reverse transcription-quantitative PCR. The expression of RGN mRNA was determined using the PrimeScript ${ }^{\mathrm{TM}}$ RT reagent kit and the SYBR Premix Ex Taq ${ }^{\mathrm{TM}}$ II kit (Takara Bio, Inc., Otsu, Japan). All steps were performed according to the manufacturer's protocols. Primer sequences were as follows: RGN forward, 5'-GTGGATGCCTTTGACTATGACC-3', and reverse, 5'-CTTCCCCTCAGCATCAATACAC-3'; GAPDH forward, 5'-CGAGATCCTCAACCAATCAA-3', and reverse
5'-GGTGGTCCAGGGTCGTTACT-3'. PCR reaction conditions were as follows: $20 \mathrm{sec}$ at $95^{\circ} \mathrm{C}, 30 \mathrm{sec}$ at $60^{\circ} \mathrm{C}$ and $30 \mathrm{sec}$ at $72^{\circ} \mathrm{C}$, repeated for 40 cycles. The $2^{-\Delta \Delta \mathrm{Cq}}$ method was used to analyze mRNA expression (18).

Western blot analysis. RGN-transfected and empty vector control cells cultured in $25 \mathrm{~cm}^{2}$ culture flasks were lysed using $500 \mu 1$ RIPA lysate supplemented with $1 \mathrm{mM}$ PMSF. The protein concentrations were determined using a bicinchoninic acid protein assay kit (Beyotime Institute of Biotechnology, Haimen, China) and $30 \mu \mathrm{g}$ total protein/lane was separated using SDS-PAGE (separation gel, 12\%; spacer gel, 5\%). The separated proteins were transferred to polyvinylidene difluoride membranes (Bio-Rad Laboratories, Inc., Hercules, CA, USA), blocked with 5\% non-fat milk and incubated with the following primary antibodies overnight at $4^{\circ} \mathrm{C}$ : RGN $(1: 1,000$; cat. no. 17947-1-AP; ProteinTech Group, Inc., Chicago, IL, USA), $\beta$-catenin (1:1,000; cat. no. 51067-2-AP; ProteinTech Group, Inc.), p-glycogen synthase kinase (GSK)-3 $\beta$ (1:1,000; cat. no. ab75814; Abcam, Cambridge, UK), GSK-3 $\beta$ (1:1,000; cat. no. 22104-1-AP; ProteinTech Group, Inc.), matrix metalloproteinase (MMP)-3 (1:1,000; cat. no. 17873-1-AP; ProteinTech Group, Inc.), MMP-7 (1:800; cat. no. 10374-2-AP; ProteinTech Group, Inc.), MMP-9 (1:800; cat. no. 10375-2-AP; ProteinTech Group, Inc.), E-cadherin (1:1,000; cat. no. 20874-1-AP; ProteinTech Group, Inc.), N-cadherin (1:1,000; cat. no. 22018-1-AP; ProteinTech Group, Inc.), Vimentin (1:1,000; cat. no. 10366-1-AP; ProteinTech Group, Inc.) and GAPDH (1:1,000; cat. no. 10494-1-AP; ProteinTech Group, Inc.). GAPDH was selected as internal reference. The membranes were washed with TBS $+0.1 \%$ Tween-20 (TBST) three times for $5 \mathrm{~min}$ and subsequently incubated with secondary goat anti-rabbit IgG-HRP (1:5,000; cat. no. E-AB-1003; Elabscience Biotechnology Co., Ltd., Wuhan, China) for $1 \mathrm{~h}$ at $37^{\circ} \mathrm{C}$. The membranes were washed with TBST three times for $10 \mathrm{~min}$. Enhanced chemiluminescence ultra-sensitive luminescence solution (Applygen, Beijing, China) was used to develop the bands. Densitometry was performed using ImageJ v1.48 software (National Institutes of Health, Bethesda, MD, USA).

Migration assay. $800 \mu 1$ /well DMEM with $10 \%$ FBS was added to a 24-well plate prior to the addition of Transwell inserts. HeLa cells $\left(3 \times 10^{4}\right)$ were resuspended in $200 \mu \mathrm{l}$ DMEM and loaded into the upper chamber. Following a $24 \mathrm{~h}$ incubation period in $37^{\circ} \mathrm{C}$, the membranes were fixed with $4 \%$ paraformaldehyde for $15 \mathrm{~min}$ at room temperature (RT) and stained with $0.1 \%$ crystal violet for $10 \mathrm{~min}$ at RT. The cells on the inner surface of membrane were removed by a cotton swab, whereas those on the outer surface were counted by an optical microscope (magnification, x400; Olympus Corporation, Tokyo, Japan) in five random fields.

Invasion assay. Cellular invasive capacity was analyzed using a Matrigel assay. Matrigel (BD Biosciences; Becton, Dickinson and Company, Franklin, Lakes, NJ, USA) was diluted with DMEM at a ratio of 1:9 and added to the upper chamber. Once the gel had set, $800 \mu$ l DMEM with $10 \%$ FBS was added to 24 -well plates, and $3 \times 10^{4}$ cells were inserted into the chamber. The cells were incubated at $37^{\circ} \mathrm{C}$ for $24 \mathrm{~h}$, fixed with $4 \%$ paraformaldehyde for $15 \mathrm{~min}$ and stained with $0.1 \%$ 
crystal violet for $10 \mathrm{~min}$ at RT. The cells on the inner surface of membrane were removed, whereas those on the outer surface were counted using an optical microscope (magnification, $\mathrm{x} 400$ ) in five random fields.

Cell proliferation assay. HeLa cells were cultured in 96-well plates $\left(3 \times 10^{3}\right.$ cells/well) for $24,48,72$ and $96 \mathrm{~h}$. The culture medium was removed and $100 \mu 1$ DMEM with $10 \%$ FBS and $10 \mu \mathrm{l}$ Cell Counting Kit-8 assay buffer (Dojindo Molecular Technologies, Inc., Kumamoto, Japan) was added to each well. Following a 4-h incubation period, the absorbance was determined at $450 \mathrm{~nm}$. The experiment was performed in triplicate.

Colony formation assay. A total of 500 cells/well were seeded into 6-well plates and gently dispersed by agitation. The cells were cultured at $37^{\circ} \mathrm{C}$ with $5 \% \mathrm{CO}_{2}$ for 14 days with frequent observation. The culture medium was discarded as soon as colonies were visible, and the wells were gently washed twice with PBS. The cells were subsequently fixed and stained with $0.1 \%$ crystal violet for $10 \mathrm{~min}$ at RT. The samples were gently washed with water and allowed to dry naturally, prior to the colonies being photographed and counted.

Cell cycle analysis. Cell cycle analysis was conducted using a cell cycle detection kit (Vazyme Piscataway, NJ, USA). $2 \times 10^{6} \mathrm{HeLa}$ cells were washed and fixed with ice-cold ethanol $(70 \%)$ for $8 \mathrm{~h}$ at $4^{\circ} \mathrm{C}$. The cells were centrifuged at $300 \mathrm{x} \mathrm{g}$ for $5 \mathrm{~min}$ at $4^{\circ} \mathrm{C}$, resuspended in $400 \mu \mathrm{l}$ PBS supplemented with $20 \mu \mathrm{l}$ RNase A solution, and incubated in a water bath at $37^{\circ} \mathrm{C}$ for $1.5 \mathrm{~h}$. Subsequently, $400 \mu \mathrm{l}$ PI Staining Solution (Beyotime Institute of Biotechnology, Shanghai, China) was added, and the cells were incubated at $4^{\circ} \mathrm{C}$ for $0.5 \mathrm{~h}$ prior to flow cytometric analysis using a flow cytometer (FACScalibur; Becton Dickinson, Cockeysville, MD, USA) and CellQuest software (Becton Dickinson).

Statistical analysis. The data are described as the mean \pm standard deviation. The experiments were performed in triplicate. Student's t-test and one-way ANOVA were used to analyze the experimental results and bioinformatics analysis. Student-Newman-Keuls post hoc test was used for multiple comparisons. $\mathrm{P}<0.05$ was considered to indicate a statistically significant difference.

\section{Results}

The expression of RGN is reduced in the cancerous tissues of patients with CESC compared with those of healthy controls. Based on clinical information in TCGA, it was revealed that the expression of RGN in CESC tissues was reduced compared with those of normal tissues (Fig. 1A), though this was not associated with individual cancer stage, patient's race, patient's weight, patient's age or histological subtype (Fig. 1B-F).

Exogenous RGN is successfully expressed in HeLa cells following lentivirus-mediated transfection. HeLa cells were infected with lentivirus-mediated RGN or empty lentivirus. The expression levels of RGN mRNA in RGN transfectants was significantly increased compared with those transfected with the empty vector (Fig. $2 \mathrm{~A} ; \mathrm{P}<0.001$ ). RGN protein expression level in the RGN transfectants was also increased significantly compared with the controls (Fig. 2B; $\mathrm{P}<0.001$ ). The results indicated that HeLa cells that highly express RGN were successfully produced.

Exogenous RGN influences the expression of $\beta$-catenin, p-GSK-3 $\beta, G S K-3 \beta, M M P-3, M M P-7, M M P-9$ and E-cadherin. The expression levels of $\beta$-catenin, $\mathrm{p}-\mathrm{GSK}-3 \beta$, GSK-3 $\beta$, MMP-3, MMP-7, MMP-9, E-cadherin, N-cadherin and vimentin were measured using western blotting. The expression levels of $\beta$-catenin, p-GSK-3 $\beta$, MMP-3, MMP-7 and MMP-9 in RGN transfectants was markedly downregulated, whilst E-cadherin and GSK-3 $\beta$ expression was upregulated (Fig. 3A). There was no significant change in the expression levels of $\mathrm{N}$-cadherin and vimentin. The ratio of phosphorylated/total GSK-3 $\beta$ is displayed in Fig. 3B, and reveals that the average ratio of phosphorylated/total GSK-3 $\beta$ in the controls was higher compared with that of the HeLa-RGN cell line. The aforementioned results indicate that exogenous RGN may effectively inhibit the Wnt/ $\beta$-catenin pathway and subsequent epithelial-mesenchymal transition (EMT).

Overexpression of $R G N$ depresses cellular migration and invasion. Transwell and Matrigel assays were used to evaluate the migration and invasion abilities of HeLa cells, respectively. Fig. 4A illustrates that the migration ability of HeLa cells was significantly depressed by RGN (number of migrated cells: $385.67 \pm 35.02$ vs. $276.33 \pm 13.32, \mathrm{P}<0.01$ ), and Fig. $4 \mathrm{~B}$ reveals that invasiveness was also depressed in RGN transfectants (number of invaded cells: $348.33 \pm 20.48$ vs. $157.00 \pm 9.14$, $\mathrm{P}<0.01)$. The aforementioned results suggest that RGN overexpression may have the ability to inhibit tumor cell metastasis.

RGN overexpression inhibits cell proliferation. Cell growth was analyzed using the CCK- 8 assay. Fig. 5A demonstrates that compared with the control group, the proliferation rate of the RGN transfectants was significantly lower at $72 \mathrm{~h}(\mathrm{P}<0.001)$. Cell proliferation was analyzed using a colony formation assay. Following 14 days of incubation, cell colonies formed of RGN transfectants were lower in number compared with those of the empty vector controls $(\mathrm{P}<0.01$; Fig. 5B). The experimental results revealed that RGN effectively inhibits HeLa cell proliferation.

$R G N$ upregulation halts the cell cycle at the $G_{2} / M$ phase. Flow cytometry was used to compare the distribution of RGN transfectants and control cells between the cell cycle phases. The number of diploid HeLa-RGN cells in the $\mathrm{G}_{2} / \mathrm{M}$ phase was greater compared with those in the control group (Fig. 6A). The proportion of RGN transfectants in the $\mathrm{G}_{2} / \mathrm{M}$ phase was higher compared with that of the empty vector transfectants $(\mathrm{P}<0.01$, Fig. 6B), which suggests that RGN may depress tumor growth by retarding the cell cycle at the $\mathrm{G}_{2} / \mathrm{M}$ phase.

\section{Discussion}

In the present study, lentivirus-mediated RGN was successfully transfected into HeLa cells, which markedly reduced cellular proliferation, migration and invasion. The effect of exogenous RGN expression on specific signaling pathways was analyzed using western blotting. The expression of $\beta$-catenin, 

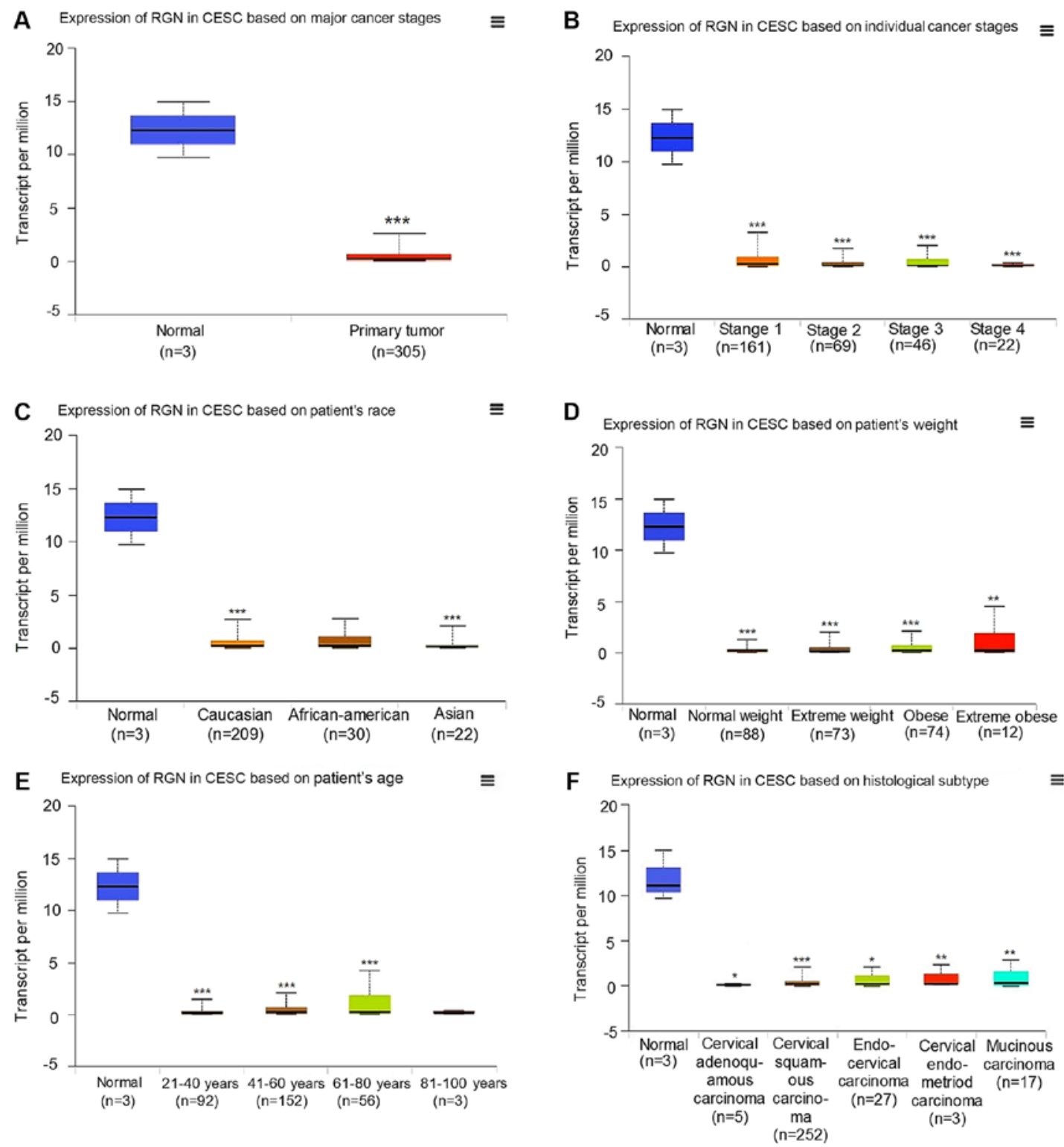

Figure 1. Expression of RGN is markedly lower in CESC patients compared with healthy controls, according to TCGA database. (A) Expression of RGN in normal individuals was notably higher compared with that in patients with primary tumors. However, there were no significant differences in RGN expression between (B) cancer stages, (C) patient's race, (D) patient's weight, (E) patient's age and (F) histological subtype. ${ }^{*} \mathrm{P}<0.05,{ }^{* *} \mathrm{P}<0.01$ and ${ }^{* * *} \mathrm{P}<0.001$ vs. normal controls. TCGA, The Cancer Genome Atlas; RGN, regucalcin; CESC, cervical and endocervical cancers.

p-GSK-3 $\beta$, MMP-3, MMP-7 and MMP-9 was downregulated, whilst E-cadherin and GSK-3 $\beta$ expression was upregulated in cells overexpressing RGN. The results suggest that RGN may regulate proliferation and metastasis of HeLa cells by blocking the activation of the Wnt/ $\beta$-catenin signaling pathway and EMT.

The inhibitory effects of RGN on cancer cell proliferation and metastasis have been reported in a number of studies. It has been demonstrated that RGN depresses H4-II-E cell proliferation by attenuating DNA synthesis, suppressing the activity of $\mathrm{Ca}^{2+} /$ calmodulin-dependent protein kinase, protein kinase $\mathrm{C}$ and protein tyrosine kinase, or by altering the mRNA expression of various intracellular signaling-associated factors, including p21 and Insulin-like growth factor 1 (19-23).

Proliferation may also be inhibited when transferring exogenous RGN into lung cancer cells, or by incubating pancreatic cancer cells with RGN-supplemented media $(24,25)$. It was also demonstrated that RGN transgenic rats possessed a lower
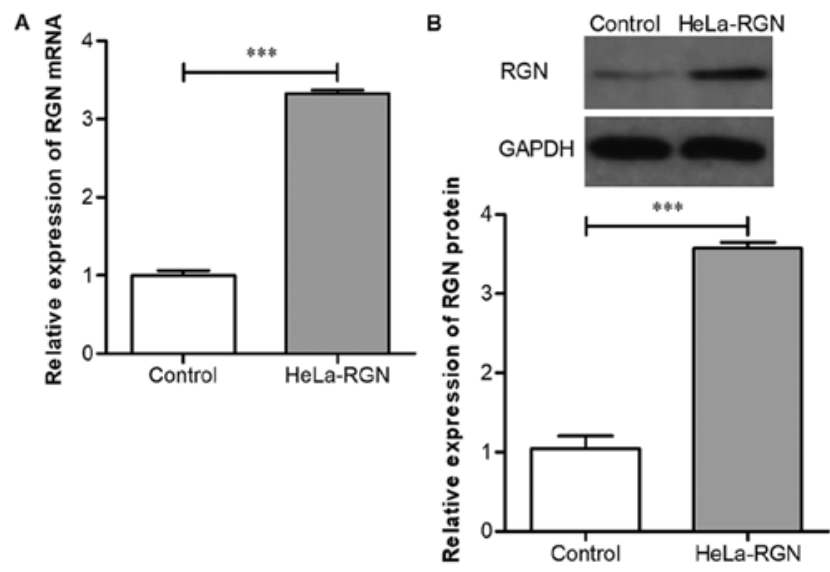

Figure 2. Lentivirus-mediated RGN upregulates the expression levels of RGN mRNA and RGN protein in HeLa cells. (A) RGN mRNA and (B) RGN protein was increased in RGN transfectants. ${ }^{* * *} \mathrm{P}<0.001$. RGN, regucalcin. 
A
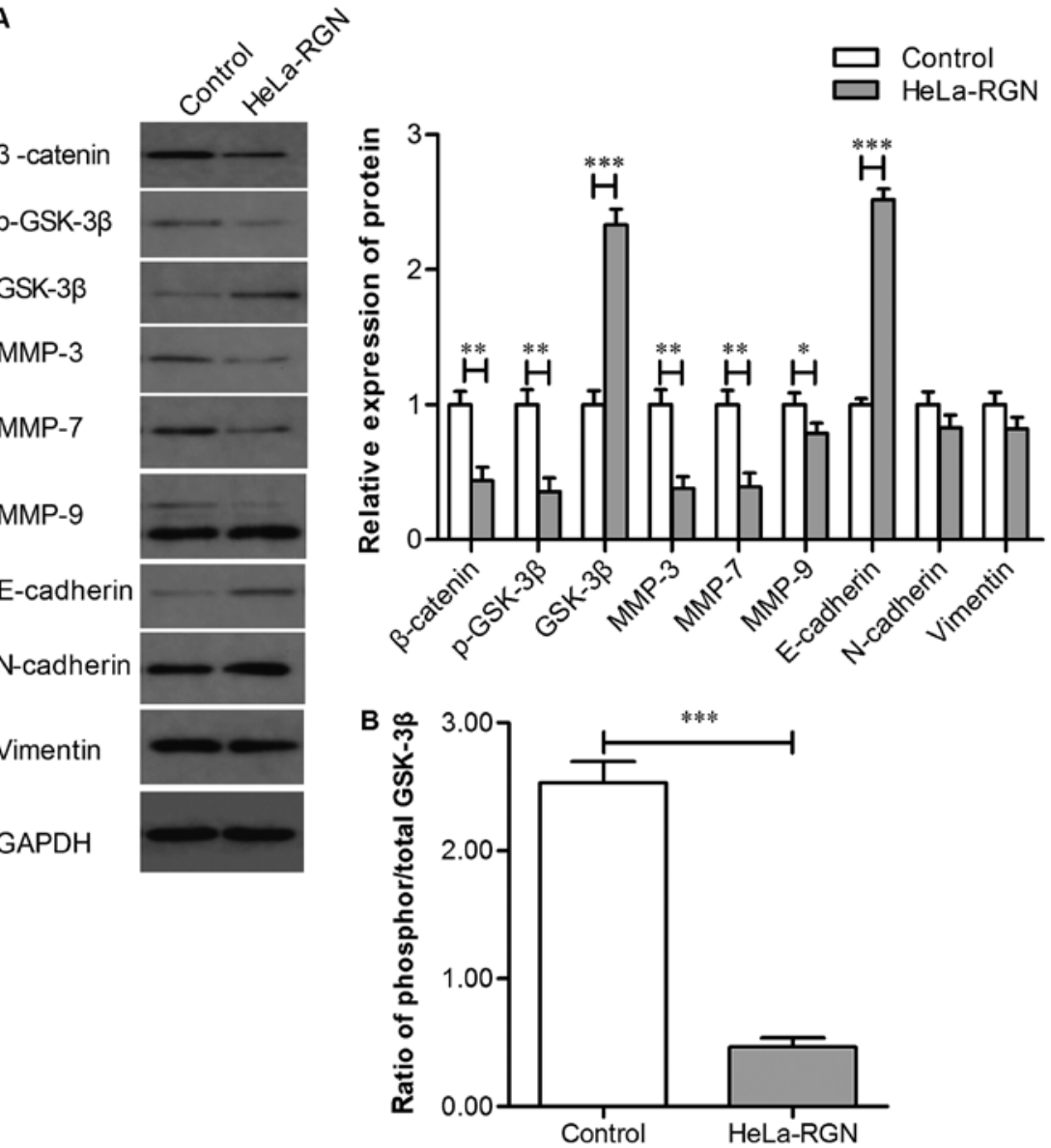

Figure 3. Influence of RGN on the Wnt/ $\beta$-catenin signaling pathway. (A) The expression of $\beta$-catenin, p-GSK-3 $\beta$, MMP-3, MMP-7 and MMP-9 were markedly downregulated, and E-cadherin and GSK-3 $\beta$ expression was markedly upregulated in RGN transfectants. (B) The average ratio of phosphorylated/total GSK-3 $\beta$ in the controls was higher compared with that in the HeLa-RGN cell line. ${ }^{*} \mathrm{P}<0.05,{ }^{* *} \mathrm{P}<0.01$ and ${ }^{* * *} \mathrm{P}<0.001$. RGN, regucalcin; GSK, glycogen synthase kinase; MMP, matrix metalloproteinase.

A

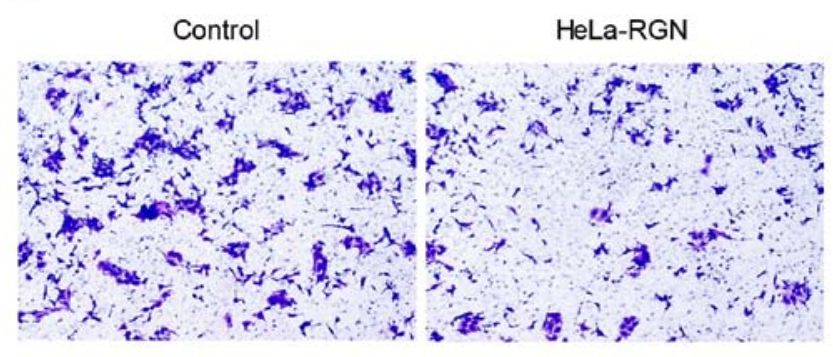

B

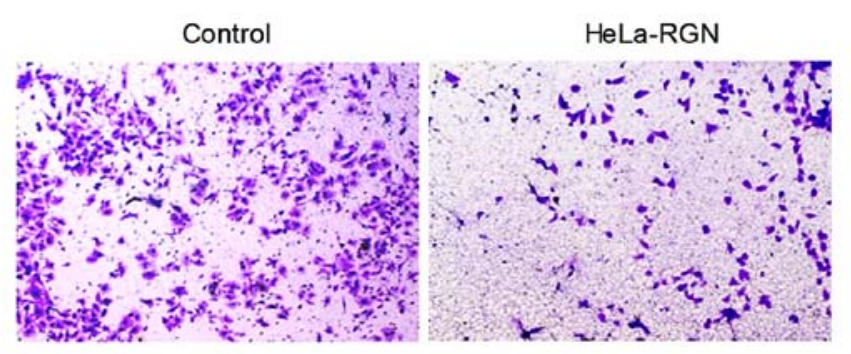

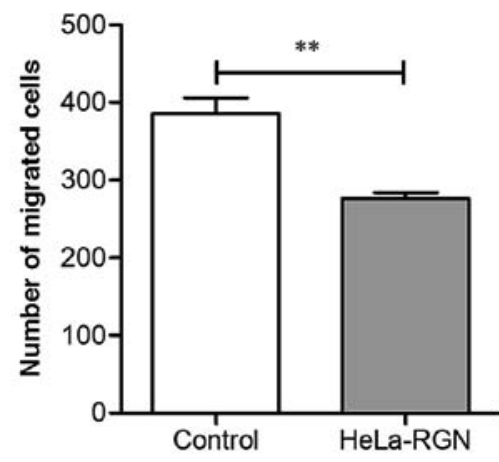

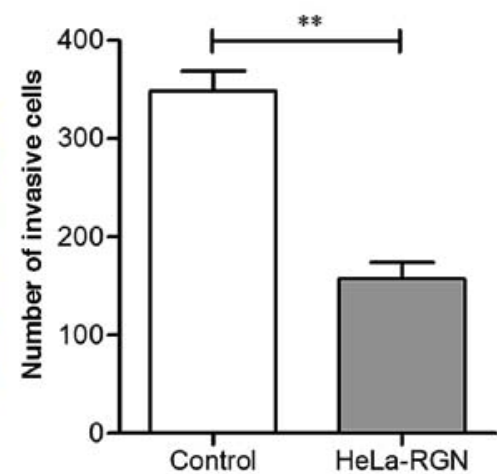

Figure 4. Overexpression of RGN depresses cell migration and invasion. The (A) migration and (B) invasion abilities of HeLa cells were significantly depressed by RGN. Magnification $x 100 .{ }^{* *} \mathrm{P}<0.01$. RGN, regucalcin. 


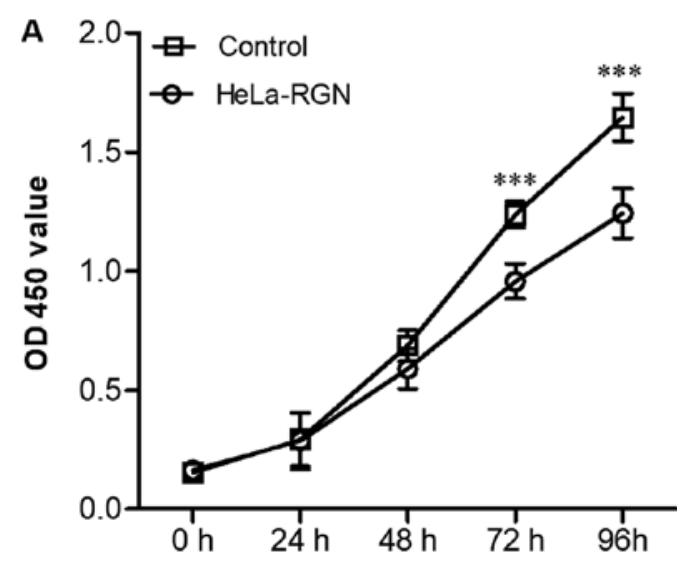

B

Control

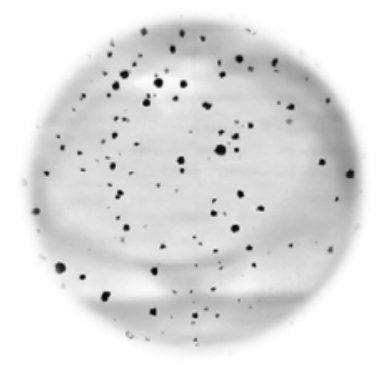

HeLa-RGN

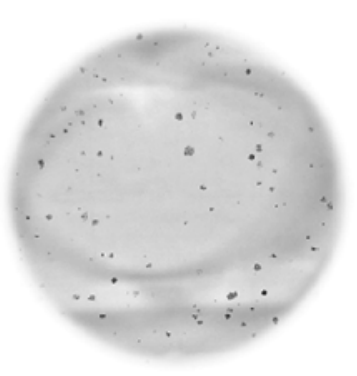

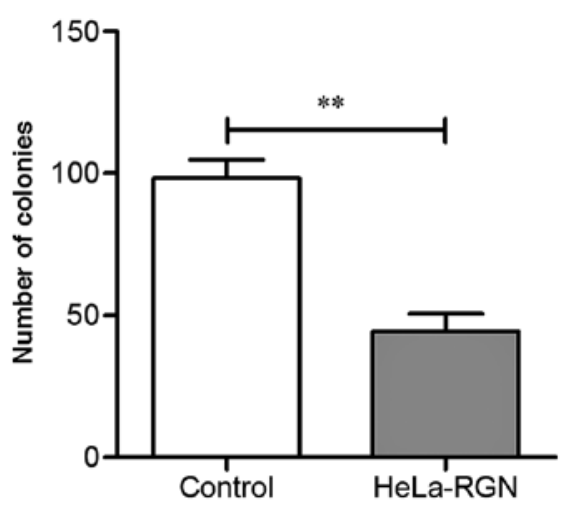

Figure 5. RGN overexpression inhibits cell proliferation. (A) Compared to the empty vector controls, the proliferation rate of the RGN transfectants was significantly attenuated. (B) Colony formation of RGN transfectants was significantly decreased. ${ }^{* *} \mathrm{P}<0.01$ and ${ }^{* * * *} \mathrm{P}<0.001$. RGN, regucalcin; OD, optical density.
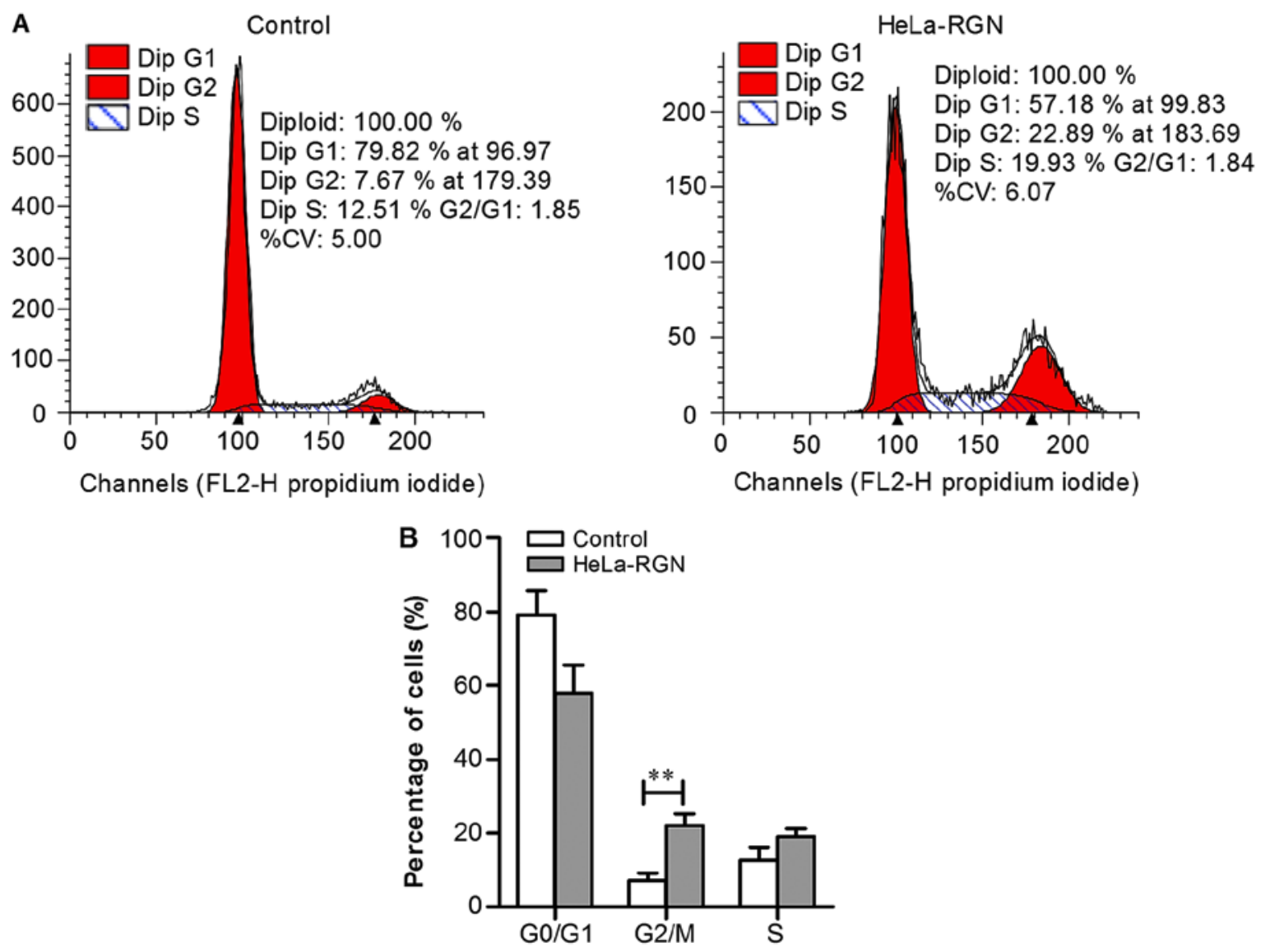

Figure 6. RGN overexpression blocks the cell cycle at the $\mathrm{G}_{2} / \mathrm{M}$ phase. (A) The number of diploid HeLa-RGN cells in the $\mathrm{G}_{2} / \mathrm{M}$ phase was higher compared with those in the control group. (B) The cell distribution in the $\mathrm{G}_{2} / \mathrm{M}$ phase was decreased in RGN transfectants compared with the control group. ${ }^{* *} \mathrm{P}<0.01$. RGN, regucalcin. 
propensity for breast cancer, in addition to lower cellular proliferation and metastasis rates $(26,27)$. More recently, Yamaguchi et al (28) reported that the overexpression of RGN in the colorectal adenocarcinoma cancer cell line, $\mathrm{RKO}$, suppressed proliferation and induced cell cycle arrest at the $G_{1}$ and $G_{2} / M$ phases. The results of the present study revealed that the proliferation, migration and invasion abilities of RGN transfectants were significantly inhibited. Yamaguchi et al $(24,28,29)$ also demonstrated that RGN promoted cell cycle arrest at the $G_{1}$ and $\mathrm{G}_{2} / \mathrm{M}$ phases in A549, HepG2 and RKO cells. The present study on HeLa cells revealed that RGN halted the cell cycle at the $G_{2} / M$ phase, but not at the $G_{1}$ phase. This suggests that the influence of RGN on the cell cycle varies between cell types.

Numerous studies have demonstrated that RGN is associated with various signaling pathways, including the nuclear factor- $\kappa \mathrm{B}, \mathrm{Akt}$, mitogen-activated protein kinase and stress-activated protein kinases/Jun amino-terminal kinases pathways $(29,30)$. The overexpression of RGN suppressed the expression of multiple oncogenes including K-ras, Ha-ras, c-fos, $c$-jun, c-myc and $c h k, 2$, or enhanced the expression of certain anti-oncogenes including $p 53$ and $R b(28,31,32)$. The $\mathrm{Wnt} / \beta$-catenin signaling pathway, which is associated with cell proliferation and metastasis, is involved in cervical carcinogenesis $(33,34)$. Wnt signaling is activated by the Frizzled family of transmembrane receptors; Wnt binding promotes the binding of $\beta$-catenin and T-cell factor/lymphoid enhancer factors in the cytosol, and their subsequent nuclear translocation; this results in the activation of target genes, including the MMPs (35-37). Prior to Wnt signaling activation, $\beta$-catenin is sequestered by E-cadherin in the cytoplasm. When $\beta$-catenin translocates to the nucleus, E-cadherin expression decreases, a phenomenon associated with EMT. During EMT, the expression of E-cadherin decreases significantly, while the expression of $\mathrm{N}$-cadherin and vimentin increases (38-40). Additionally, the enhancement of GSK-3 $\beta$ activity results in the ubiquitination, and subsequent phosphorylation and degradation $\beta$-catenin (41). In the present study, $\beta$-catenin, p-GSK-3 $\beta$, MMP-3, MMP-7 and MMP-9 expression were downregulated, while E-cadherin and GSK-3 $\beta$ expression were upregulated in RGN transfectants, indicating that exogenous RGN expression may inhibit the activation of Wnt/ $\beta$-catenin signaling, enhance cell adhesion and alter cell morphology to an epithelial phenotype.

In conclusion, the present study may suggest that RGN is a protective factor in CA. Though the association between RGN, Wnt/ $\beta$-catenin and EMT requires further investigation.

\section{Acknowledgements}

Not applicable.

\section{Funding}

The present study was supported by the National Natural Science Foundation of China (grant no. 81460432, 81572994); Guangxi Nature Science Foundation (grant nos. 2015GXNSFDA139017, 2015GXNSFBA139155 and 2017GXNSFAA198063); Guangxi Science and Technology Research and Technology Development Project (grant no. 15104001-7); Guangxi Nanning Qingxiu District Science and Technology Research and Technology Development Project (grant no. 2014S03) and the Open Fund of Guangxi Key Laboratory of Biological Targeting Diagnosis and Therapy Research (grant no. KFJJ2014-03).

\section{Availability of data and materials}

All data generated or analyzed during the present study are included in this publication.

\section{Authors' contributions}

SZ and XL conceived the study. XL and YH were major contributors in writing the manuscript. SZ, XL, YH, SG, MX, $\mathrm{XB}, \mathrm{MS}, \mathrm{AC}, \mathrm{SC}, \mathrm{FW}$ and $\mathrm{QH}$ performed the experiments and data analysis. All authors read and approved the final manuscript.

\section{Ethics approval and consent to participate}

Not applicable.

\section{Patient consent for publication}

Not applicable.

\section{Competing interests}

The authors declare that they have no competing interests.

\section{References}

1. Yamaguchi M and Sugii K: Properties of calcium-binding protein isolated from the soluble fraction of normal rat liver. Chem Pharm Bull (Tokyo) 29: 567-570, 1981.

2. Yamaguchi $M$ and Yoshida $H$ : Regulatory effect of calcium-binding protein isolated from rat liver cytosol on activation of fructose 1,6-diphosphatase by $\mathrm{Ca} 2+-$-calmodulin. Chem Pharm Bull (Tokyo) 33: 4489-4493, 1985.

3. Yamaguchi $\mathrm{M}$ and Mori S: Effect of $\mathrm{Ca} 2+$ and $\mathrm{Zn} 2+$ on 5'-nucleotidase activity in rat liver plasma membranes: Hepatic calcium-binding protein (regucalcin) reverses the $\mathrm{Ca} 2+$ effect. Chem Pharm Bull (Tokyo) 36: 321-325, 1988.

4. Yamaguchi M, Mori S and Suketa Y: Effects of Ca2+ and V5+ on glucose-6-phosphatase activity in rat liver microsomes: The $\mathrm{Ca} 2+$ effect is reversed by regucalcin. Chem Pharm Bull (Tokyo) 37: 388-390, 1989.

5. Yamaguchi $\mathrm{M}$ and Shibano $\mathrm{H}$ : Effect of calcium-binding protein on the activation of phosphorylase a in rat hepatic particulate glycogen by Ca2+. Chem Pharm Bull (Tokyo) 35: 2581-2584, 1987.

6. Yamaguchi M and Shibano H: Calcium-binding protein isolated from rat liver cytosol reverses activation of pyruvate kinase by Ca2+. Chem Pharm Bull (Tokyo) 35: 2025-2029, 1987.

7. Yamaguchi $M$ and Shibano $H$ : Reversible effect of calcium-binding protein on the $\mathrm{Ca} 2+$-induced activation of succinate dehydrogenase in rat liver mitochondria. Chem Pharm Bull (Tokyo) 35: 3766-3700, 1987.

8. Yamaguchi M, Mori S and Kato S: Calcium-binding protein regucalcin is an activator of $(\mathrm{Ca} 2+-\mathrm{Mg} 2+)$-adenosine triphosphatase in the plasma membranes of rat liver. Chem Pharm Bull (Tokyo) 36: 3532-3539, 1988.

9. Zhang SC, Liang MK, Huang GL, Jiang K, Zhou SF and Zhao S: Inhibition of SMP30 gene expression influences the biological characteristics of human Hep G2 cells. Asian Pac J Cancer Prev 15: 1193-1196, 2014.

10. Denny L: Cervical cancer: Prevention and treatment. Discov Med 14: 125-131, 2012.

11. Bray F, Ferlay J, Soerjomataram I, Siegel RL, Torre LA and Jemal A: Global cancer statistics 2018: GLOBOCAN estimates of incidence and mortality worldwide for 36 cancers in 185 countries. CA Cancer J Clin 68: 394-424, 2018. 
12. Smith HO, Tiffany MF, Qualls CR and Key CR: The rising incidence of adenocarcinoma relative to squamous cell carcinoma of the uterine cervix in the United States-a 24-year populationbased study. Gynecol Oncol 78: 97-105, 2000.

13. Galic V, Herzog TJ, Lewin SN, Neugut AI, Burke WM, Lu YS, Hershman DL and Wright JD: Prognostic significance of adenocarcinoma histology in women with cervical cancer. Gynecol Oncol 125: 287-291, 2012.

14. Shimada M, Kigawa J, Nishimura R, Yamaguchi S, Kuzuya K, Nakanishi T, Suzuki M, Kita T, Iwasaka T and Terakawa N Ovarian metastasis in carcinoma of the uterine cervix. Gynecol Oncol 101: 234-237, 2006.

15. Huang YT, Wang CC, Tsai CS, Lai CH, Chang TC, Chou HH, Hsueh S, Chen CK, Lee SP and Hong JH: Long-term outcome and prognostic factors for adenocarcinoma/adenosquamous carcinoma of cervix after definitive radiotherapy. Int J Radiat Oncol Biol Phy 80: 429-436, 2011.

16. Katanyoo K, Tangjitgamol S, Chongthanakorn M, Tantivatana T, Manusirivithaya S, Rongsriyam K and Cholpaisal A: Treatment outcomes of concurrent weekly carboplatin with radiation therapy in locally advanced cervical cancer patients. Gynecol Oncol 123: 571-576, 2011.

17. Yee GP, de Souza P and Khachigian LM: Current and potential treatments for cervical cancer. Curr Cancer Drug Targets 13: 205-220, 2013.

18. Kubista M, Andrade JM, Bengtsson M, Forootan A, Jonák J, Lind K, Sindelka R, Sjöback R, Sjögreen B, Strömbom L, et al: The real-time polymerase chain reaction. Mol Aspects Med 27: 95-125, 2006.

19. Inagaki $S$ and Yamaguchi M: Suppressive role of endogenous regucalcin in the enhancement of protein kinase activity with proliferation of cloned rat hepatoma cells (H4-II-E). J Cell Biochem Suppl 36 (Suppl): S12-S18, 2001.

20. Inagaki S and Yamaguchi M: Regulatory role of endogenous regucalcin in the enhancement of nuclear deoxyribonuleic acid synthesis with proliferation of cloned rat hepatoma cells (H4-II-E). J Cell Biochem 82: 704-711, 2001.

21. Misawa H, Inagaki S and Yamaguchi M: Suppression of cell proliferation and deoxyribonucleic acid synthesis in the cloned rat hepatoma H4-II-E cells overexpressing regucalcin. J Cell Biochem 84: 143-149, 2001.

22. Yamaguchi M and Daimon Y: Overexpression of regucalcin suppresses cell proliferation in cloned rat hepatoma H4-II-E cells: Involvement of intracellular signaling factors and cell cycle-related genes. J Cell Biochem 95: 1169-1177, 2005.

23. Yamaguchi M: Role of regucalcin in maintaining cell homeostasis and function (review). Int J Mol Med 15: 371-389, 2005.

24. Yamaguchi M, Osuka S, Shoji M, Weitzmann MN and Murata T: Survival of lung cancer patients is prolonged with higher regucalcin gene expression: Suppressed proliferation of lung adenocarcinoma A549 cells in vitro. Mol Cell Biochem 430: 37-46, 2017.

25. Yamaguchi $M$ and Murata T: Suppressive effects of exogenous regucalcin on the proliferation of human pancreatic cancer MIA PaCa-2 cells in vitro. Int J Mol Med 35: 1773-1778, 2015.

26. Marques R, Vaz CV, Maia CJ, Gomes M, Gama A, Alves G, Santos CR, Schmitt F and Socorro S: Histopathological and in vivo evidence of regucalcin as a protective molecule in mammary gland carcinogenesis. Exp Cell Res 330: 325-335, 2015.

27. Maia C, Santos C, Schmitt F and Socorro S: Regucalcin is under-expressed in human breast and prostate cancers: Effect of sex steroid hormones. J Cell Biochem 107: 667-676, 2009.

28. Yamaguchi M, Osuka S, Murata T: Prolonged survival of patients with colorectal cancer is associated with a higher regucalcin gene expression: Overexpression of regucalcin suppresses the growth of human colorectal carcinoma cells in vitro. Int J Oncol 53: $1313-1322,2018$
29. Yamaguchi M, Osuka S, Weitzmann MN, El-Rayes BF, Shoji M and Murata T: Prolonged survival in hepatocarcinoma patients with increased regucalcin gene expression: HepG2 cell proliferation is suppressed by overexpression of regucalcin in vitro. Int $\mathrm{J}$ Oncol 49: 1686-1694, 2016.

30. Yamaguchi M, Osuka S, Weitzmann MN, El-Rayes BF, Shoji M and Murata T: Prolonged survival in pancreatic cancer patients with increased regucalcin gene expression: Overexpression of regucalcin suppresses the proliferation in human pancreatic cancer MIA PaCa-2 cells in vitro. Int J Oncol 48: 1955-1964, 2016.

31. Tsurusaki Y and Yamaguchi M: Role of regucalcin in liver nuclear function: Binding of regucalcin to nuclear protein or DNA and modulation of tumor-related gene expression. Int $\mathbf{J} \mathrm{Mol}$ Med 14: 277-281, 2004.

32. Tsurusaki Y and Yamaguchi M: Overexpression of regucalcin modulates tumor-related gene expression in cloned rat hepatoma H4-II-E cells. J Cell Biochem 90: 619-626, 2003.

33. Jacques BE, Montgomery WH IV, Uribe PM, Yatteau A, Asuncion JD, Resendiz G, Matsui JI and Dabdoub A: The role of $\mathrm{Wnt} / \beta$-catenin signaling in proliferation and regeneration of the developing basilar papilla and lateral line. Dev Neurobiol 74: 438-456, 2014.

34. Bahrami A, Hasanzadeh M, ShahidSales S, Yousefi Z, Kadkhodayan S, Farazestanian M, Joudi Mashhad M, Gharib M, Mahdi Hassanian S and Avan A: Clinical significance and prognosis value of Wnt signaling pathway in cervical cancer. J Cell Biochem 118: 3028-3033, 2017.

35. Burgy $\mathrm{O}$ and Königshoff M: The WNT signaling pathways in wound healing and fibrosis. Matrix Biol 68-69: 67-80, 2018.

36. Kypta RM and Waxman J: Wnt/ $\beta$-catenin signalling in prostate cancer. Nat Rev Urol 9: 418-428, 2012.

37. Wang X, Su GY, Zhao C, Qu FZ, Wang P and Zhao YQ: Anticancer activity and potential mechanisms of $1 \mathrm{C}$, a ginseng saponin derivative, on prostate cancer cells. J Ginseng Res 42: 133-143, 2018.

38. Cong N, Du P, Zhang A, Shen F, Su J, Pu P, Wang T, Zjang J, Kang $C$ and Zhang Q: Downregulated microRNA-200a promotes EMT and tumor growth through the wnt/ $\beta$-catenin pathway by targeting the E-cadherin repressors ZEB1/ZEB2 in gastri adenocarcinoma. Oncol Rep 29: 1579-1587, 2013.

39. Xu HG, Zheng Q, Song JX, Li J, Wang H, Liu P, Wang J, Wang CD and Zhang XL: Intermittent cyclic mechanical tension promotes endplate cartilage degeneration via canonical Wnt signaling pathway and E-cadherin/ $\beta$-catenin complex cross-talk. Osteoarthritis Cartilage 24: 158-168, 2016.

40. Zhang X, Yang M, Shi H, Hu J, Wang Y, Sun Z and Xu S: Reduced E-cadherin facilitates renal cell carcinoma progression by $\mathrm{WNT} / \beta$-catenin signaling activation. Oncotarget 8 : 19566-19576, 2017.

41. Fang X, Yu SX, Lu Y, Bast RC Jr, Woodgett JR and Mills GB: Phosphorylation and inactivation of glycogen synthase kinase 3 by protein kinase A. Proc Natl Acad Sci USA 97:11960-11965, 2000 .

This work is licensed under a Creative Commons Attribution-NonCommercial-NoDerivatives 4.0 International (CC BY-NC-ND 4.0) License. 